\title{
Characterization of Transition-Metal Oxide Deposition on Carbon Electrodes of a Supercapacitor
}

\author{
Ying-Chung Chen ${ }^{1}$, Chih-Yu Wen ${ }^{1}$, Chih-Ming Wang ${ }^{2, *}$, Chia-Wei Ho ${ }^{1}$, Shih-Yuan Lin ${ }^{1}$ \\ and Ying-Lin Chen ${ }^{1}$ \\ 1 Department of Electrical Engineering, National Sun Yat-Sen University, Kaohsiung 804, Taiwan; \\ ycc@mail.ee.nsysu.edu.tw (Y.-C.C.); kood1555@gmail.com (C.-Y.W.); \\ m993010002@student.nsysu.edu.tw (C.-W.H.); d943010004@gmail.com (S.-Y.L.); \\ m003010062@student.nsysu.edu.tw (Y.-L.C.) \\ 2 Department of Electrical Engineering, Cheng Shiu University, Kaohsiung 833, Taiwan \\ * Correspondence: cmwang@gcloud.csu.edu.tw; Tel.: +886-7-7310606; Fax: +886-7-7337390 \\ Academic Editor: Jiazhao Wang \\ Received: 30 September 2016; Accepted: 5 December 2016; Published: 7 December 2016
}

\begin{abstract}
In order to fabricate the composite electrodes of a supercapacitor, transition-metal oxide materials $\mathrm{NiO}$ and $\mathrm{WO}_{3}$ were deposited on carbon electrodes by electron beam evaporation. The influences of various transition-metal oxides, scan rates of cyclic voltammograms (CVs), and galvanostatic charge/discharge tests on the characteristics of supercapacitor were studied. The charge/discharge efficiency and the lifetime of the composite electrodes were also investigated. It was found that the composite electrodes exhibited more favorable capacitance properties than those of the carbon electrodes at high scan rates. The results revealed the promotion of the capacitance property of the supercapacitor with composite electrode and the improving of the decay property in capacitance at high scan rate. In addition, the charge/discharge efficiency is close to $100 \%$ after 5000 cycles, and the composite electrode retains strong adhesion between the electrode material and the substrate.
\end{abstract}

Keywords: electron beam evaporation; composite electrode; supercapacitor; charge/discharge efficiency

\section{Introduction}

A supercapacitor is a new storage device positioned between traditional capacitors and batteries. Electrochemically activated materials or porous materials are used for storage in a supercapacitor. The advantages of a supercapacitor are its high power density, high energy density, excellent cycle life, and fast charge and discharge times [1,2]. Supercapacitors have attracted considerable attention in recent years because they do not have the disadvantages that traditional batteries and capacitors have.

It has been discovered that charges can be separated using Coulomb electrostatic force and form double layers across the surface of electrodes and electrolytes [3]. The concept of an electrical double-layer capacitor (EDLC) involves applying DC voltage to electrodes, which are typically porous carbon, to establish an electrical double-layer for charges storage. A pseudocapacitor stores electrical energy through rapid and continuous redox reactions between the electrodes and the electrolyte. Metal oxides and conducting polymers are commonly used as the electrode materials in pseudocapacitors. Porous carbon is usually chosen as the electrode material in commercial products because of the high cost of metal oxides and the poor stability of the conducting polymers. Therefore, composite electrodes exhibit such advantages as double-layer capacitance and pseudo-capacitance [4,5]. 
Beliakov et al. prepared an asymmetrical composite electrode by using $\mathrm{NiO}$ and carbon in 1999, and the results showed more favorable energy density than carbon-carbon electrodes [6]. However, Takasu et al. in 1999 proposed a oxide composite consisting of Ti, V, and $\mathrm{W}$ oxides for the application of ECs [7]; meanwhile Jeong and Manthiram reported that $\mathrm{RuO}_{2}$ coated with $\mathrm{WO}_{3}$ showed good capacitive performances in both acidic and alkaline media in 2001 [8,9]. In 2005, Yuan et al. showed a hybrid-type electrochemical capacitor, in which the activated-carbon (AC) load with nickel oxide was used as cathode material and the activated-carbon was used as anode material. Although the BET surface area of the activated-carbon decreased after nickel oxide loading compared with that of the starting material, its specific capacitance increased $10.84 \%$, from 175.40 to $194.01 \mathrm{~F} \cdot \mathrm{g}^{-1}[10,11]$. Recently, amorphous tungsten oxide with microwave radiation was reported to be a promising electrode material for electrochemical capacitors (ECs) [12]. Accordingly, tungsten oxides and $\mathrm{NiO}$ of certain microstructures should be of pseudocapacitive behavior.

In this study, the carbon electrode using mesocarbon microbeads (MCMBs) was adopted for the fabrication of a supercapacitor. To fabricate the composite electrodes of the supercapacitor, $\mathrm{NiO}$ and $\mathrm{WO}_{3}$ layers were deposited onto carbon electrodes using electron beam evaporation. This technique, one of the physical vapor deposition methods, was chosen largely for the growth of device quality films [13]. The influences of various scan rates of the cyclic voltammograms (CVs) on the characteristics of capacitance were studied. The charge/discharge efficiency and lifetime of the composite electrodes were also discussed.

\section{Experimental}

\subsection{Preparation of Carbon Electrodes}

Conductivity percolation was found to play a critical role in determining the electrochemical capacitive behavior of the carbon-carbon composite electrode, which is comprised of a non-conductive activated carbon with a large surface area and a conductive carbon black (CB) with a small surface area [14]. Therefore, CB powder (10 wt \%) was added to $1 \mathrm{~g}$ of MCMB powder and mixed uniformly. The mixing powder was added to a solution containing $2 \mathrm{wt} \%$ polyvinyl butyral (PVB) and $9.1 \mathrm{mg}$ of dimethylacetamide (DMA). The mixture was mixed at room temperature (R.T.) to form a carbon slurry. The electrodes were prepared by spin-coating the carbon slurry onto ITO glass (transmittance of $85 \%$, sheet resistance of $15 \Omega \cdot \mathrm{sq}^{-1}$.) and then evaporating the solvent, DMA, in an oven at $150{ }^{\circ} \mathrm{C}$ for $10 \mathrm{~min}$.

\subsection{Fabrication of Composite Electrodes}

First, $\mathrm{WO}_{3}$ and $\mathrm{NiO}$ were, respectively, deposited using an electron beam evaporation technique onto the MCMB/ITO substrates. A high-purity $\mathrm{WO}_{3}$ powder (99.8\%, Alfa Aesar, Heysham, UK) and a $\mathrm{NiO}$ powder ( $99 \%$, Sigma-Aldrich, St. Louis, MO, USA) were used as the evaporation materials. The vacuum chamber was initially pumped to a pressure of $5 \times 10^{-6}$ Torr before evaporation. A working pressure of approximately $1 \times 10^{-5}$ Torr was maintained throughout the evaporating process. The distance between the powder and the substrate was $20 \mathrm{~cm}$. The powders were heated using an electron beam that was collimated from the DC heated cathode of a tungsten filament. The surface of the powders was scanned using a $270^{\circ}$ deflected electron beam at an accelerating voltage of $4 \mathrm{kV}$. The thickness of the films and the deposition rate were controlled using the quartz crystal monitor. Prior to evaporation, a pre-evaporating process was performed for $5 \mathrm{~min}$ to remove contaminants from the powder.

$\mathrm{MCMB} / \mathrm{ITO}$ glass was used as the substrate. Continuous rotation of the substrates during the deposition process facilitated the formation of homogeneous and uniform films on the substrate surface. The evaporation rate of $0.5 \mathrm{~nm} \cdot \mathrm{s}^{-1}$ was adopted to deposit all films. The preparation flow diagram of composite electrodes is shown in Figure 1. 


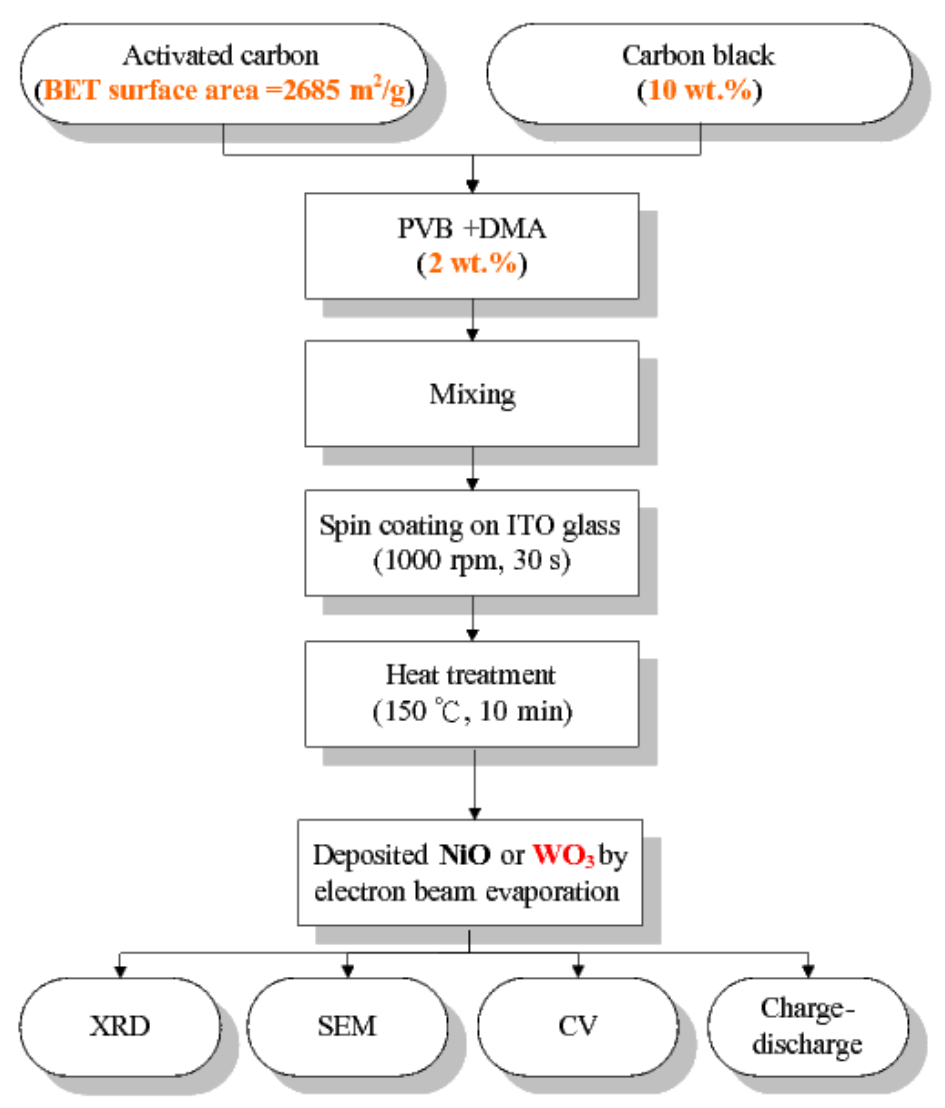

Figure 1. The preparation flow diagram of the composite electrode.

\subsection{Characterization and Electrochemical Properties}

The crystalline structure of the films was analyzed using X-ray diffraction (XRD, PANalytical $X^{\prime}$ Pert PRO, Almelo, Netherlands) with $\mathrm{Cu} K \alpha$ radiation $(\lambda=0.1542 \mathrm{~nm})$. Step scans performed at a scan rate of $3^{\circ} \cdot \mathrm{min}^{-1}$ were performed in the $2 \theta$ ranged from $10^{\circ}$ to $70^{\circ}$. The thickness and surface microstructures of the films were investigated using a scanning electron microscope (SEM, ZEISS, Auriga-39-50, Oberkochen, Germany). The characterization of the electrochemical properties was conducted in a 2-electrode cell by using an electrochemical analyzer (CHI, 6273B, Austin, TX, USA). The CVs curves were used to analyze the voltage and current changes, which used $1 \mathrm{M} \mathrm{Et}_{4} \mathrm{NBF}_{4}$ as an electrolyte and scanned at a scan rate of $25 \mathrm{mV} \cdot \mathrm{s}^{-1}$ and at a voltage range of $\cdot 3 \mathrm{~V}$ to $3 \mathrm{~V}$. The following equation was used to calculate the specific capacitance [15]:

$$
C=\frac{d Q}{d V}=4 \times \frac{1}{m v \Delta V} \int_{V_{1}}^{V_{2}} I(V) d V
$$

where $\int_{V_{1}}^{V_{2}} I(V) d V$ is the hysteresis loop area, $v$ is the scan rate, $\Delta V$ is the range of potential, and $m$ is the total weight of the electrode material.

\section{Results and Discussion}

Figure 2 shows that the carbon electrode prepared using the MCMB was in an amorphous state. According to the JCPDS cards, peaks at $37.2^{\circ}$ and $43.2^{\circ}$ of $2 \theta$ correspond to the (111) and (200) diffractions of $\mathrm{NiO}$ (JCPDS files: 20-1324) deposited on the carbon electrode. However, there were not obvious diffraction peaks for $\mathrm{WO}_{3}$ deposited on the carbon electrode; therefore, it was in an amorphous state. Because $\mathrm{WO}_{3}$ films were deposited at R.T., the amount of energy was insufficient to induce crystalline growth. 


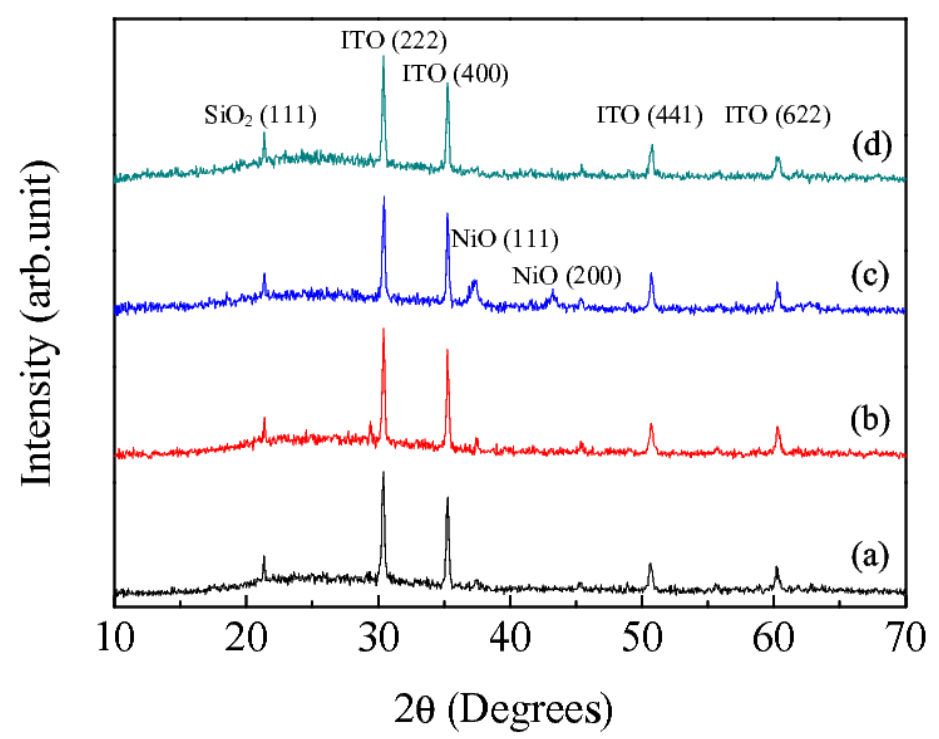

Figure 2. X-ray patterns of the composite electrodes: (a) ITO/glass substrate; (b) MCMB/ITO/glass; (c) $\mathrm{NiO} / \mathrm{MCMB} / \mathrm{ITO} /$ glass; (d) $\mathrm{WO}_{3} / \mathrm{MCMB} / \mathrm{ITO} /$ glass.

Figure 3 shows the morphologies of a layer $\mathrm{NiO}$ deposited on the activated carbon surface. The $\mathrm{WO}_{3}$ films deposited on the activated carbon are round rock structures as shown in Figure 4 . Cracks are visible on the $\mathrm{WO}_{3}$ films. The MCMB has a high specific surface area and porosity. The thickness of the metal oxide $\left(\mathrm{WO}_{3}\right.$ or $\left.\mathrm{NiO}\right)$ films deposited on the MCMB surface is about $500 \mathrm{~nm}$ via electron beam evaporation. This caused cracks, but a high power density of the supercapacitor with composite structure electrodes was obtained. Electrochemical measurements were conducted in a 2-electrode disc-type cell (capacitor), in which a separator was soaked in $1 \mathrm{M} \mathrm{Et}_{4} \mathrm{NBF}_{4}$ and inserted between the two carbon electrodes. A voltage ranges of -3.0 to $3.0 \mathrm{~V}$ was applied.

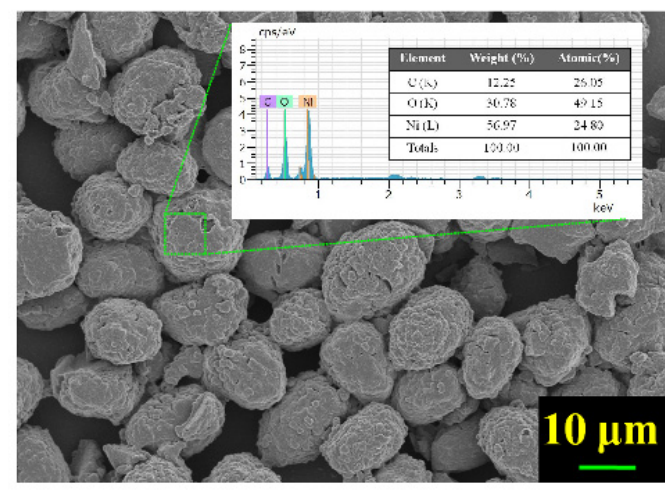

(a)

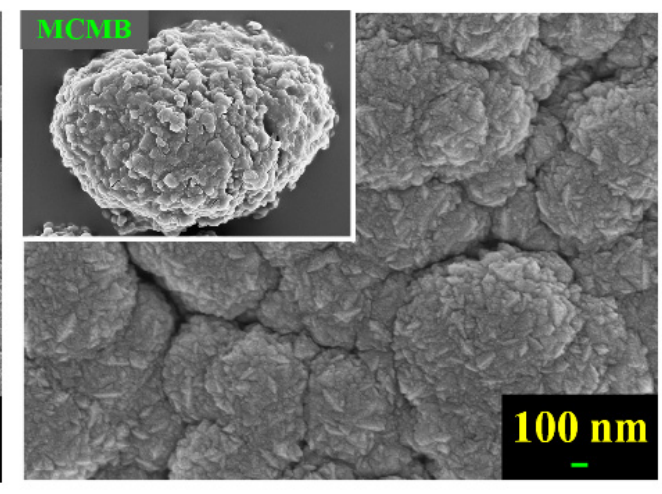

(b)

Figure 3. SEM morphologies and EDS of the NiO thin films deposited on the carbon electrode: (a) the magnification of $1000 \times(\mathbf{b})$ the magnification of $30,000 \times$. 


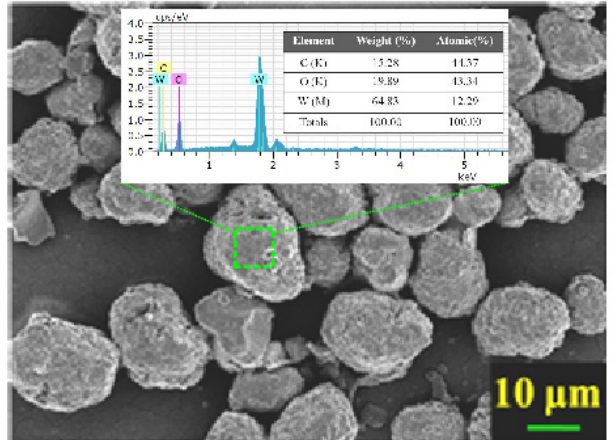

(a)

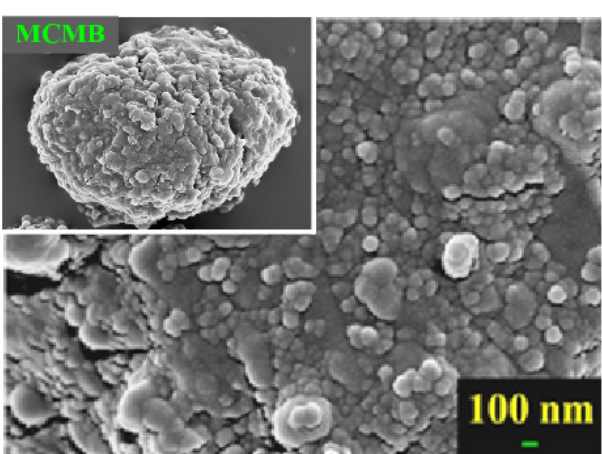

(b)

Figure 4. SEM morphologies and EDS of the $\mathrm{WO}_{3}$ thin films deposited on the carbon electrode: (a) the magnification of $1000 \times($ b) the magnification of $30,000 \times$.

While at lower scan rates all the active surface area can be utilized for charge storage [16]. Therefore, a smooth current peak was obtained. However, the current peak increased with the increasing scan rate. As the scan rate of the CVs gradually increased, the shape of the CVs changed from rectangular to ovular. In Figure 5, when the scan rate was $25-200 \mathrm{mV} \cdot \mathrm{s}^{-1}$, carbon electrodes and composite electrodes exhibited a similar hysteresis area of CVs. However, when the scan rate exceeded $250 \mathrm{mV} \cdot \mathrm{s}^{-1}$, the hysteresis area of the CVs of the composite electrodes was larger than that of the carbon electrodes. The composite electrode, on which $\mathrm{NiO}$ was deposited, exhibited a larger hysteresis area.
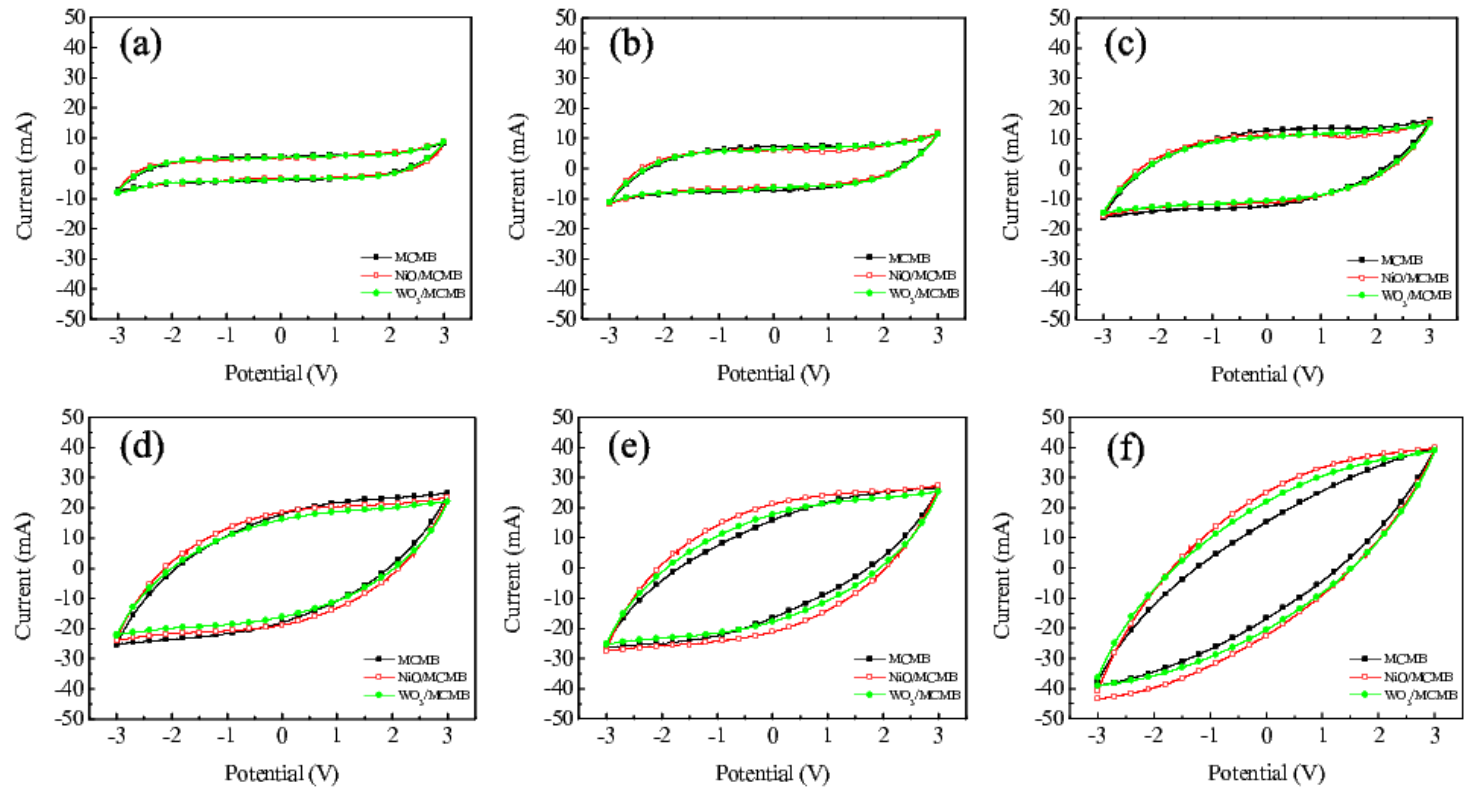

Figure 5. $\mathrm{CVs}$ of the carbon electrodes and the composite electrodes in $1 \mathrm{M} \mathrm{Et}_{4} \mathrm{NBF}_{4}$ solution at various scan rates: (a) $25 \mathrm{mV} / \mathrm{s}$ (b) $50 \mathrm{mV} / \mathrm{s}$ (c) $100 \mathrm{mV} / \mathrm{s}$ (d) $200 \mathrm{mV} / \mathrm{s}$ (e) $250 \mathrm{mV} / \mathrm{s}$ (f) $500 \mathrm{mV} / \mathrm{s}$.

Table 1 shows the specific capacitances that were calculated using Equation (1) at various scan rates of CVs. Specific capacitances decreased gradually when scan rates increased, as shown in Figure 6. When the voltage scan rate was slower, a chemical adsorption/desorption or redox reaction occurred on the surfaces of the electrodes, enabling electrolyte ions to migrate into the inner pores of the electrodes. The ions may not have had enough time to reach the surface of the capacitor electrode at a high scan rate. However, when the scan rate was slower, the redox reaction occurred on the surfaces of 
the electrodes, enabling ions to migrate into the inner pores of the electrodes. Therefore, a low scan rate demonstrates a better specific capacitance for devices. As a result, when the electrode with a large specific surface area is adopted, the specific capacitance is increased [17-19].

Table 1. The specific capacitance $\left(\mathrm{F} \cdot \mathrm{g}^{-1}\right)$ of the composite electrode at various scan rates.

\begin{tabular}{cccc}
\hline Scan rates & MCMB & NiO/MCMB & WO3/MCMB \\
\hline $\mathbf{2 5} \mathbf{~} \mathbf{~ V / s}$ & 221.5 & 187.2 & 194.8 \\
$\mathbf{5 0} \mathbf{~ V V / s}$ & 186.4 & 146.5 & 160.4 \\
$\mathbf{1 0 0} \mathbf{~}$ V/s & 150.1 & 119.6 & 122.7 \\
$\mathbf{2 0 0} \mathbf{~ V V} / \mathbf{s}$ & 101.7 & 94.1 & 84.3 \\
$\mathbf{2 5 0} \mathbf{~} V / \mathbf{s}$ & 71.4 & 84.2 & 72.5 \\
$\mathbf{5 0 0} \mathbf{~}$ V/s & 26.7 & 41.2 & 39.3 \\
\hline
\end{tabular}

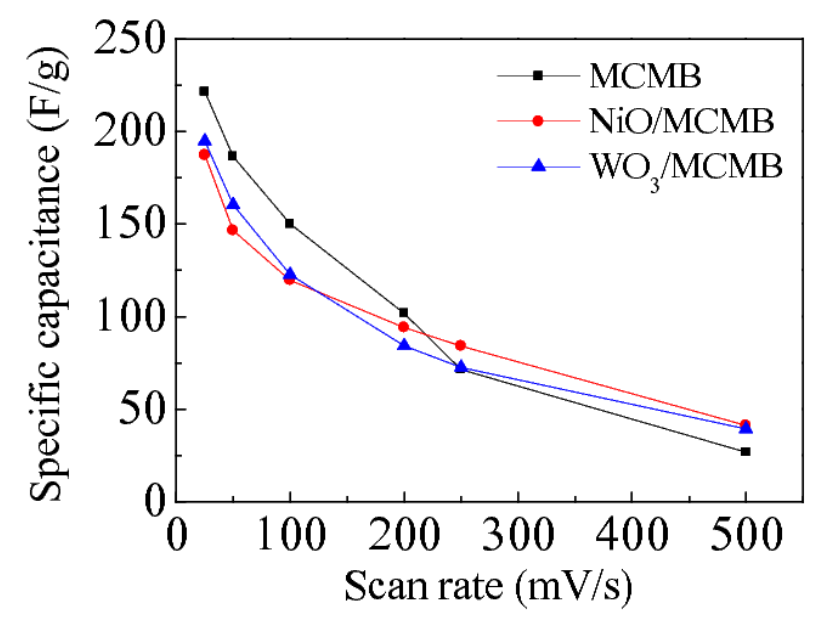

Figure 6. Specific capacitances of the carbon electrodes and the composite electrodes at various scan rates.

When the scan rate was lower than $200 \mathrm{mV} \cdot \mathrm{s}^{-1}$, the specific capacitance of the carbon electrodes was larger than the specific capacitance of the composite electrodes. The specific capacitance of the composite electrodes was larger when the scan rate was larger than $250 \mathrm{mV} \cdot \mathrm{s}^{-1}$. Because metal oxide was deposited only on the surface of the MCMB, a section of the pores was blocked, and the specific capacitance of the composite electrodes was smaller than the specific capacitance of the carbon electrodes. However, a chemical adsorption/desorption or redox reaction occurred on the surfaces of the electrodes at a high scan rate; therefore, the capacitance was excellent.

The charging and discharging curves of the $\mathrm{NiO} / \mathrm{MCMB}$ electrodes at R.T. in a voltage range of -3 to $3 \mathrm{~V}$ at a constant current density of $6 \mathrm{~A} \cdot \mathrm{g}^{-1}$ is shown in Figure $7 \mathrm{a}$. The equivalent series resistance (ESR) of the devices was calculated according to the following equation [20]:

$$
E S R=\frac{i R_{d r o p}}{2 \times I}
$$

where I (ampere of $0.03 \mathrm{~A}$ ) is the discharge current, and $i R_{\text {drop }}$ (volts of $2 \mathrm{~V}$ ) is defined as the electrical potential difference between the two ends of a conducting phase during charging/discharging. The ESR is calculated as $33.3 \Omega\left(I=0.03 \mathrm{~A}, i R_{\text {drop }}=2 \mathrm{~V}\right)$.

The electrochemical stability of the $\mathrm{NiO} / \mathrm{MCMB}$ electrodes was also studied. Figure $7 \mathrm{~b}$ shows the composite electrode test charge/discharge efficiently $(\eta)$ at 5000 cycles. The following equation was used to calculate the charge/discharge efficiently:

$$
\eta=\frac{Q_{d c h}}{Q_{c h}} \times 100 \%=\frac{t_{d c h}}{t_{c h}} \times 100 \%
$$


where $Q_{d c h}$ is the discharge capacity (Coulomb), $Q_{c h}$ is the charge capacity, $t_{d c h}$ is the discharge time, $t_{c h}$ is the charge time.
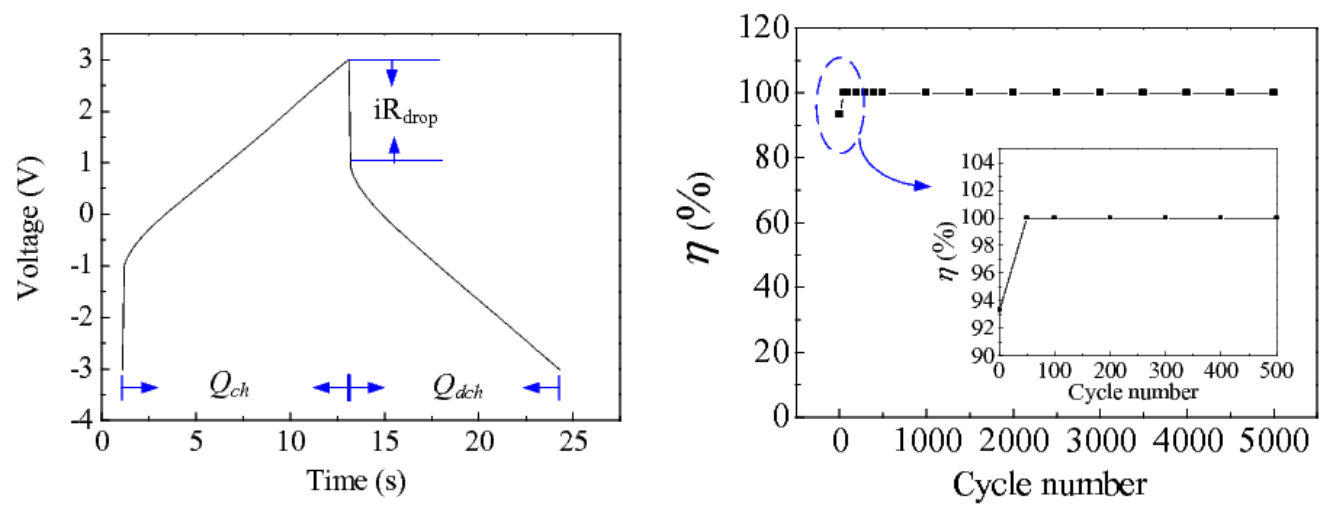

Figure 7. (a) Charging and discharging curves of the NiO/MCMB elextrodes (b) The relation of charge/discharge ( $\eta$ ) and life-times in the $\mathrm{NiO} / \mathrm{MCMB}$ elextrode.

The results show that the first charge/discharge efficiency was $93 \%$. As the charge/discharge times increased, the charge/discharge efficiency gradually increased. The charge/discharge efficiency was near $100 \%$ after 10 cycles. After 5000 cycles, good adhesion was retained between the electrode material and the substrates.

\section{Conclusions}

In this study, the carbon electrode was prepared via spin coating. Furthermore, the transition metal oxide was deposited on the surface of the electrode via electron beam evaporation, because this method produces composite electrodes with a shorter process time and less pollution than other methods.

Although the specific capacitance of a supercapacitor cannot be enhanced, the capacitance characteristics of the supercapacitor at a high scan rate can be improved. When the scan rate increased from $25 \mathrm{mV} \cdot \mathrm{s}^{-1}$ to $500 \mathrm{mV} \cdot \mathrm{s}^{-1}$, the hysteresis area of the $\mathrm{CVs}$ increased, and the shape of the CVs changed from rectangular to ovular, but the specific capacitance gradually decreased. The specific capacitance of the carbon electrode decreased from $221.5 \mathrm{Fg}^{-1}$ to $26.7 \mathrm{Fg}^{-1}$; therefore, the rate of decline was $88 \%$. The specific capacitance of the $\mathrm{NiO} / \mathrm{MCMB}$ composite electrode decreased from 187.2 $\mathrm{Fg}^{-1}$ to $41.2 \mathrm{Fg}^{-1}$, which resulted in a $78 \%$ rate of decline. The specific capacitance of the composite $\mathrm{WO}_{3} / \mathrm{MCMB}$ electrode decreased from $194.8 \mathrm{Fg}^{-1}$ to $39.3 \mathrm{Fg}^{-1}$; therefore, the rate of decline was $80 \%$. As a result, the composite electrodes reduced the rate of decline as the scan rate increased. In addition, the charge/discharge efficiency was close to $100 \%$ after 5000 cycles, and the composite electrodes retained strong adhesion between the electrode material and the substrate.

Acknowledgments: This study was supported by the Ministry of Science and Technology of the Republic of China, Taiwan, under contract number MOST 104-2221-E-230-008.

Author Contributions: Chih-Yu Wen conceived and designed the experiments; Chih-Ming Wang and Ying-Chung Chen supervised the project; Chia-Wei Ho performed the experiments; Ying-Lin Chen and Shih-Yuan Lin analyzed the data; Chih-Ming Wang contributed reagents/materials/analysis tools; Chih-Yu Wen wrote the paper.

Conflicts of Interest: The authors declare no conflict of interest.

\section{References}

1. Inagaki, M.; Konno, H.; Tanaike, O. Carbon materials for electrochemical capacitors. J. Power Source 2010, 195, 7880-7903. [CrossRef]

2. Fritts, D.H. An analysis of electrochemical capacitors. J. Electrochem. Soc. 1997, 144, 2233-2241. [CrossRef] 
3. Beliakov, A.I.; Brintsev, A.M. Proceedings of the 9th International Seminar on Double Layer Capacitors and Similar Energy Storage Devices, Deerfield Beach, FL, USA, 6-8 December 1999.

4. Ma, Y.; Tai, C.-W.; Gustafsson, T.; Edström, K. Recycled poly(vinyl alcohol) sponge for carbon encapsulation of size-tunable tin dioxide nanocrystalline composites. ChemSusChem 2015, 8, 2084-2092. [CrossRef] [PubMed]

5. Ma, Y.; Tai, C.-W.; Younesi, R.; Gustafsson, T.; Lee, J.-Y.; Edström, K. Iron doping in spinel $\mathrm{NiMn}_{2} \mathrm{O}_{4}$ : stabilization of the mesoporous cubic phase and kinetics activation toward highly reversible $\mathrm{Li}^{+}$storage. Chem. Mater. 2015, 27, 7698-7709. [CrossRef]

6. Brunauer, S.; Emmett, P.H.; Teller, E. Adsorption of gases in multimolecular layers. J. Am. Chem. Soc. 1938, 60, 309-319. [CrossRef]

7. Takasu, Y.; Mizutani, S.; Kumagai, M.; Sawaguchi, S.; Murakami, Y. Ti-V-W-O/Ti oxide electrodes as candidates for electrochemical capacitors. Electrochem. Sol. State Lett. 1999, 2, 1-2. [CrossRef]

8. Jeong, Y.-U.; Manthiram, A. Amorphous tungsten oxide/ruthenium oxide composites for electrochemical capacitors. J. Electrochem. Soc. 2001, 148, A189-A193. [CrossRef]

9. Chang, K.-H.; Hu, C.-C.; Huang, C.-M.; Liu, Y.-L.; Chang, C.-I. Microwave-assisted hydrothermal synthesis of crystalline $\mathrm{WO}_{3}-\mathrm{WO}_{3} \cdot 0.5 \mathrm{H}_{2} \mathrm{O}$ mixtures for pseudocapacitors of the asymmetric type. J. Power Source 2011, 196, 2387-2392. [CrossRef]

10. Yuan, G.-H.; Jiang, Z.-H.; Aramata, A.; Gao, Y.Z. Electrochemical behavior of activated-carbon capacitor material loaded with nickel oxide. Carbon 2005, 43, 2913-2917. [CrossRef]

11. Wu, M.-S.; Wang, M.-J.; Jow, J.-J. Fabrication of porous nickel oxide film with open macropores by electrophoresis and electrodeposition for electrochemical capacitors. J. Power Source 2010, 195, 3950-3955. [CrossRef]

12. Huang, C.-C.; Xing, W.; Zhuo, S.-P. Capacitive performances of amorphous tungsten oxide prepared by microwave irradiation. Scr. Mater. 2009, 61, 985-987. [CrossRef]

13. Miyake, K.; Kaneko, H.; Sano, M.; Suedomi, N. Physical and electrochromic properties of the amorphous and crystalline tungsten oxide thick films prepared under reducing atmosphere. J. Appl. Phys. 1984, 55, 2747-2753. [CrossRef]

14. Wu, N.-L.; Wang, S.-Y. Conductivity percolation in carbon-carbon supercapacitor electrodes. J. Power Source 2002, 110, 233-236. [CrossRef]

15. Bard, A.J.; Faulkner, L.R. Electrochemical Principles, Methods, and Applications; Oxford University: Oxford, UK, 1996.

16. Landgrebe, A.R. Power Sources for Transportation Applications: Proceedings of the International Symposium; The Electrochemical Society: Pennington, NJ, USA, 2004; 2003-24; pp. 1-252.

17. Zheng, J.-P.; Jow, T.-R. A new charge storage mechanism for electrochemical capacitors. J Electrochem. Soc. 1995, 142, L6-L8. [CrossRef]

18. Srinivasan, V.; Weidner, J.W. An electrochemical route for making porous nickel oxide electrochemical capacitors. J Electrochem. Soc. 1997, 144, L210-L213. [CrossRef]

19. Lin, C.; Ritter, J.A.; Popov, B.N. Development of carbon-metal oxide supercapacitors from Sol-Gel derived carbon-ruthenium xerogels. J. Electrochem. Soc. 1999, 146, 3155-3160. [CrossRef]

20. Meng, C.; Liu, C.; Chen, L.; Hu, C.; Fan, S. Highly flexible and all-solid-state paperlike polymer supercapacitors. Nano Lett. 2010, 10, 4025-4031. [CrossRef] [PubMed]

(C) 2016 by the authors; licensee MDPI, Basel, Switzerland. This article is an open access article distributed under the terms and conditions of the Creative Commons Attribution (CC-BY) license (http:/ / creativecommons.org/licenses/by/4.0/). 